\title{
Growth of pineapple plantlets during acclimatisation can be monitored through automated image analysis of the canopy
}

\author{
Guillermo Soto ${ }^{1}$, Gustavo Lorente ${ }^{1}$, Jessica Mendoza ${ }^{1}$, Evelio Dany Báez ${ }^{1}$, Carlos Manuel Lorenzo ${ }^{1}$, \\ Romelio Rodríguez ${ }^{1}$, Elliosha Hajari², Oscar Vicente ${ }^{3, *}$, José Carlos Lorenzo ${ }^{1}$, Evelio Luis Baez ${ }^{1}$
}

\begin{abstract}
Pineapple is an economically important tropical fruit crop, but the lack of adequate planting material limits its productivity. A range of micropropagation protocols has been developed over the years to address this shortfall. Still, the final stage of micropropagation, i.e. acclimatisation, remains a challenge as pineapple plantlets grow very slowly. Several studies have been conducted focusing on this phase and attempting to improve plantlet growth and establishment, which requires tools for the non-destructive evaluation of growth during acclimatisation. This report describes the use of semi-automated and automated image analysis to quantify canopy growth of pineapple plantlets, during five months of acclimatisation. The canopy area progressively increased during acclimatisation, particularly after 90 days. Regression analyses were performed to determine the relationships between the automated image analysis and morphological indicators of growth. The mathematical relationships between estimations of the canopy area and the fresh and dry weights of intact plantlets, middle-aged leaves (D leaves) and roots showed determination coefficients (R2) between 0.84 and 0.92 . We propose an appropriate tool for the simple, objective and non-destructive evaluation of pineapple plantlets growth, which can be generally applied for plant phenotyping, to reduce costs and develop streamlined pipelines for the assessment of plant growth.
\end{abstract}

Keywords Ananas comosus (L.) Merr; image analysis; acclimatisation; large-scale propagation; micropropagation

${ }^{1}$ Bioplant Center, University of Ciego de Ávila, Ciego de Ávila, 69450, Cuba.

${ }^{2}$ Plant Improvement; Agricultural Research Council-Tropical and Subtropical Crops;

Private Bag X11208, Nelspruit, 1200, South Africa.

${ }^{3}$ Institute for the Conservation and Improvement of Valencian Agrodiversity (COMAV), Universitat Politècnica de

València, 46022 Valencia, Spain.

${ }^{*}$ Corresponding author: O. Vicente E-mail: ovicente@upvnet.upv.es

DOI: $10.2478 /$ ebtj-2020-0026

(C) 2020 Authors. This work was licensed under the Creative Commons AttributionNonCommercial-NoDerivs 4.0 License.

\section{Introduction}

Pineapple [Ananas comosus (L.) Merr] is a monocotyledonous, herbaceous perennial crop valued for its fruit. It is the only species in the Bromeliaceae family that is cultivated commercially. In this regard, pineapple represents the third most important tropical fruit worldwide, in terms of production, after banana and mango (1-3). At present, pineapple is grown on more than one million hectares, with most of the harvested fruit destined for the fresh produce market in Europe and North America. The economic importance of pineapple is emphasised by the fact that the gross production value of the 24.8 million metric tons of fruit that are produced annually, is in the region of $9 \times 109$ US\$ (4). However, a severe restriction that hampers production is inadequate access to pineapple planting material of good quality $(5,6)$. To address this problem, alternative propagation methods have been investigated. In this regard, micropropagation techniques in tissue culture have been considered to rapidly multiply superior genotypes under controlled conditions in the laboratory $(5,7-12)$. The final stage of micropropagation, i.e. acclimatisation, presents a challenge in the case of pineapple since plants grow at a very slow rate during this process, which increases the time needed to release the plants and has associated cost implications (13-15). Several strategies have been employed to promote faster and more efficient acclimatisation of pineapple plants, including the use of nitrogen-fixing microorganisms (16) and modifications in light supply, irrigation and fertilisation (17-19). Assessing the effi- 
cacy of these and other growth stimulatory treatments would be greatly facilitated if simple, non-destructive methods were available for the evaluation of pineapple growth during the acclimatisation process.

Image analysis has been used for a range of diverse applications in plant sciences. For example, in a plant phenotyping study, semi-automated image analysis was combined with machine learning algorithms to quantify root system architectural traits (20). Similarly, fully automated image analysis has been used to identify quantitative trait loci in roots for plant phenotyping (21). Other authors showed that digital image analysis could be used for the real-time estimation of the leaf chlorophyll content of micropropagated potato plants, and suggested that this parameter could represent a quality control indicator to assess the photosynthetic and hyperhydric status of tissue-cultured plants during acclimatisation (22). Niazian et al. (23) used image analysis to determine the physical properties of ajowan embryogenic callus; subsequently, artificial neural network models were applied to predict the properties of the produced calli, depending on culture media and other input variables. In the context of plant diseases, the severity of Fusarium Head Blight on the surface of grains has been quantified by an image analysis method that was recommended as being inexpensive, objective and fast, in comparison with current methods involving visual detection (24). Also, Wang et al. (25) described a combination of image analysis and deep learning to estimate the severity of apple black rot. The effects of abiotic stress on plants can also be evaluated by image analysis, as shown in a detailed study undertaken to assess the efficiency of hyperspectral imaging in a high-throughput phenotyping platform for early detection of water stress in plants (26). However, to our knowledge, canopy growth of pineapple in vitro-plantlets during acclimatisation has not yet been monitored through automated image analysis.

Considering the ideas and examples above, the present study evaluated the use of semi-automated and automated image analysis as tools to quantify canopy growth (superior projected area) in pineapple in vitro cultured plantlets, during five months of acclimatisation. The applicability of these methods was assessed using regression analyses to determine the relationship between the image analysis methods and morphological growth indicators

\section{Materials and Methods}

\section{Plant material and growth conditions}

Pineapple buds (cv. MD-2) were initiated from field-grown plants, according to Daquinta and Benegas (7). Following a year of micropropagation, plantlets were acclimatised (13) in 250 plastic bags with Ferralitic red soil and sugarcane filter cake (1:1, v:v). Relative humidity was maintained at $80 \pm 3 \%$, the temperature at $25.5 \pm 2{ }^{\circ} \mathrm{C}$, and the photosynthetic photon flow at $400 \pm 25 \mu \mathrm{mol} \mathrm{m}-2 \mathrm{~s}-1$. Daily microjet irrigation for $30 \mathrm{~min}$ (8:00 - 8:30 a.m.) was applied. The canopies of three blocks of 56 plantlets each were photographed (Cannon EOS $600 \mathrm{D})$ from a height of $1.3 \mathrm{~m}$ at $0,1,2,3,4$ and 5 months. A separate group of plantlets, grown in parallel under the same conditions, were destructively harvested to determine fresh and dry weights (including all leaves, stem and roots) and D leaf (middle-aged leaf) (27). Ten plantlets were harvested each month for destructive measurements ( $\mathrm{n}=60$ plantlets in total). Image analysis

For canopy image analysis, two procedures were compared: semi-automated and automated analysis. For the semi-automated method, Paint.net (v4.013, tools: magic wand - contiguous and global saturation mode; bucket of paint and eraser) were used. On the other hand, image analysis for the automated system included image capturing in RGB format (Red, Green, Blue; 5,184-pixel x 3,456-pixel; vertical: 72 pixels per inch; horizontal: 72 pixels per inch), followed by a series of processing steps. The image of the RGB colour system was first converted to the HSI (Hue, Saturation, Intensity) colour system, which disregards the effect of lighting conditions when photos were taken. Then, images were segmented, allowing for differentiation of pineapple leaves from the picture background by the $\mathrm{H}$ component. After that, small 'holes' detected in the leaves were filled, and finally, the number of pixels belonging to the pineapple plantlet leaves were counted and converted to $\mathrm{cm} 2$, which represented the canopy area.

\section{Statistical analysis}

Data were analysed using SPSS (Version 8.0 for Windows, SPSS Inc., New York, NY) to perform One-Way ANOVA and Tukey tests. Regression analyses and R2 were calculated in Microsoft Excel.

\section{Results}

The use of image analysis to monitor canopy development represents one of the many applications of this technique, as mentioned above. In the present study, observation of the canopy of pineapple in vitro plantlets during acclimatisation showed that the canopy area progressively increased during the first five months of ex vitro growth (Fig. 1).

MMA common trend was observed for the fresh and dry mass of whole plantlets, D leaves and roots, i.e. there was little mass gain at first, followed by an exponential increase in mass for the subsequent months (Fig. 2A-F). A sharp increase in mass was found after one month for fresh and dry weight of whole plantlets and following two to three months of growth for the other parameters measured.

A linear regression was performed to evaluate the relationship between the canopy area data obtained using the semi-automated (x) and automated (y) methods (Fig. 3A). The results from this regression analysis showed that $99.15 \%$ of variations in automated data (y) resulted from variations in semi-automated data $(x)$ [determination coefficient $(R 2)=0.9915$ ]. Fig. $3 \mathrm{~B}$ shows the progression of canopy development over the five months monitored with automated image analysis. These results indicate that canopy area increased significantly at each sampling stage except for the second month (where there was a non-significant increase in canopy area). 
30

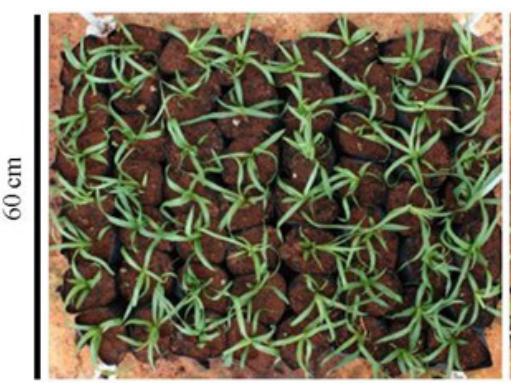

90

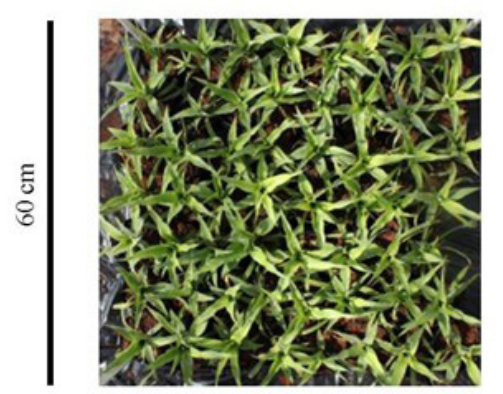

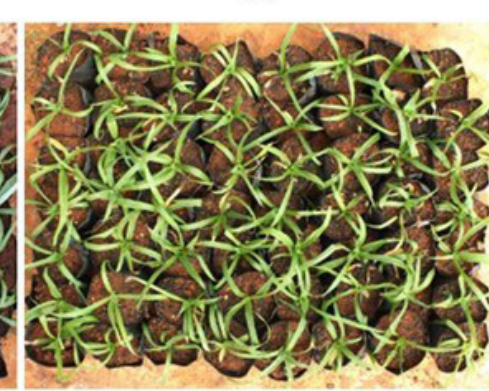

120

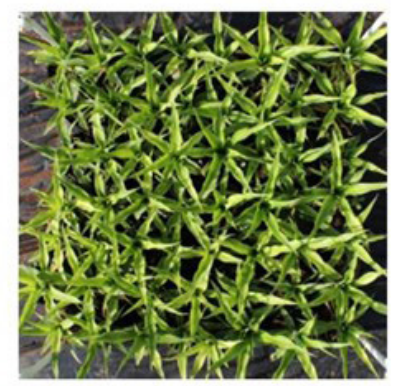

60

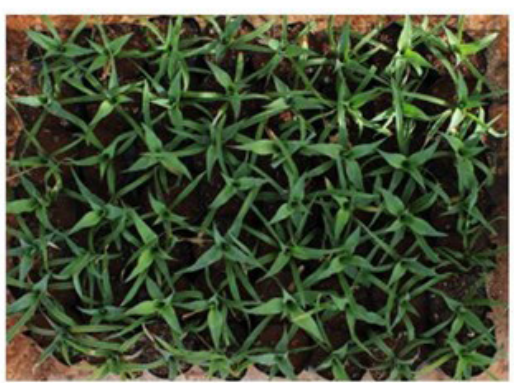

150

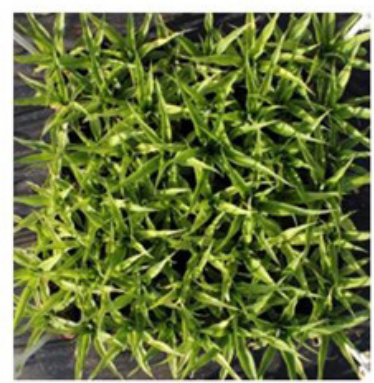

Fig. 1: Canopy growth of 56 pineapple plantlets during acclimatisation .
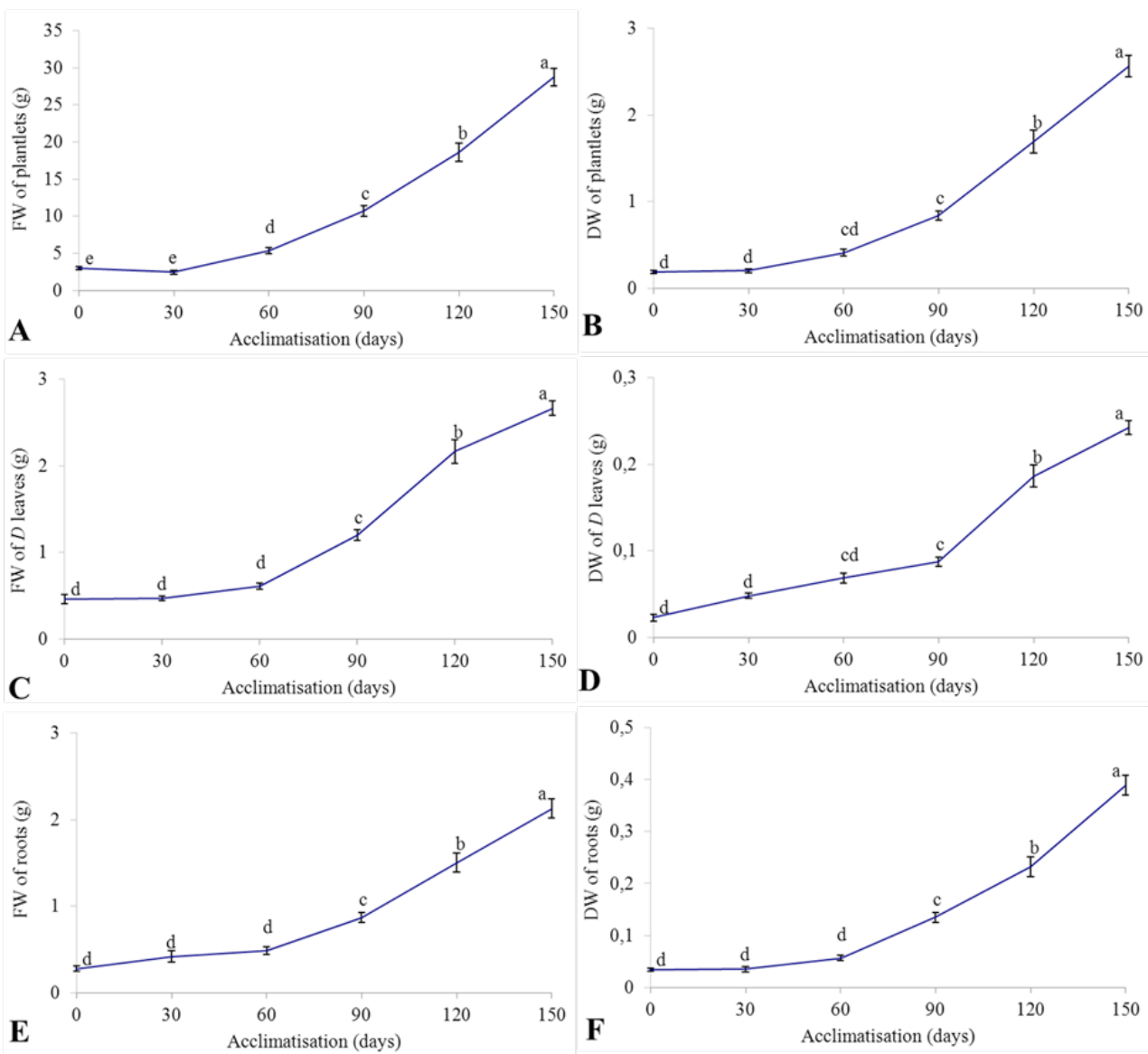

Fig. 2: Growth of individual pineapple plantlets during acclimatisation. A, C, E: Fresh weights (FW) of plantlets, leaves and roots, respectively. B $\mathrm{D}$, F: Dry weights (DW) of plantlets, leaves and roots, respectively. Results with the same letters are not statistically different (One-Way ANOVA, Tukey, $\mathrm{p}>0,05)$. Vertical bars represent $\mathrm{SE}$. 

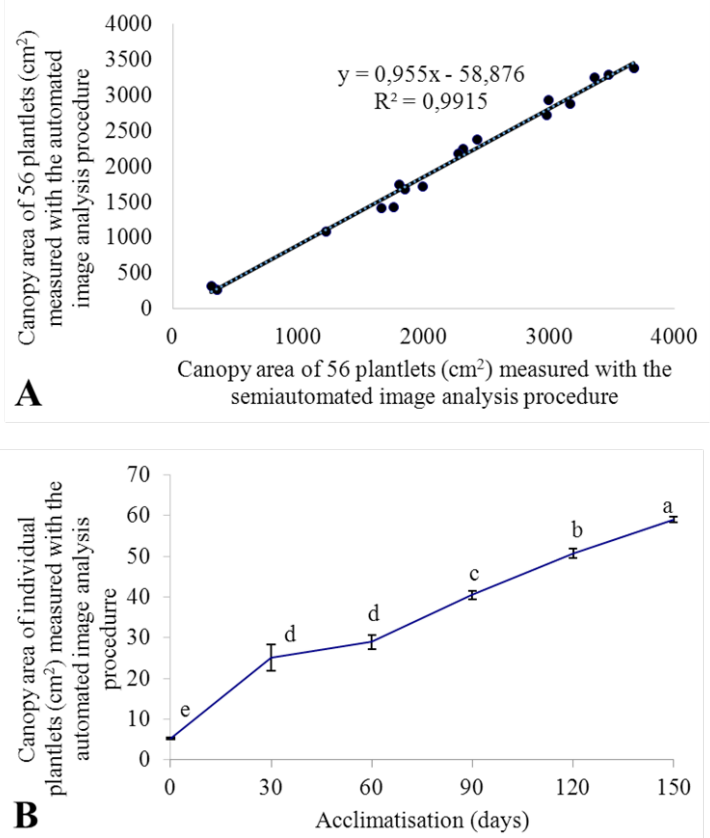

Fig. 3: Relationship between canopy area of 56 pineapple plantlets measured with the automated and semiautomated image analysis procedures (A); and canopy area of individual plantlet during acclimatisation (B). In $\mathrm{A}, \mathrm{R}^{2}$ is statistically different from cero $(\mathrm{p} \leq 0,05 ; \mathrm{n}=18)$. In $\mathrm{B}$, results with the same letters are not statistically different (OneWay ANOVA, Tukey, $p>0,05$ ) and vertical bars represent SE.

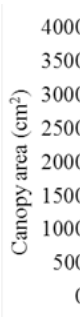

A

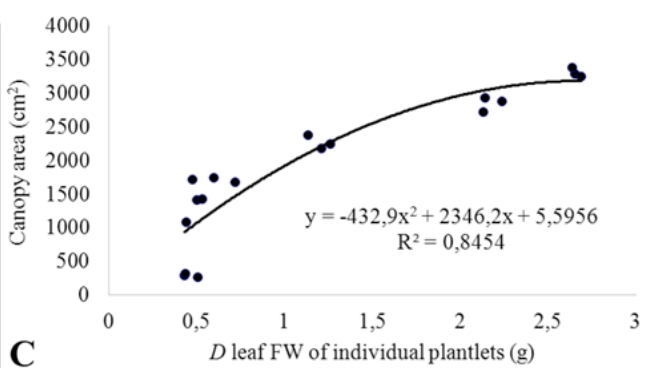

C

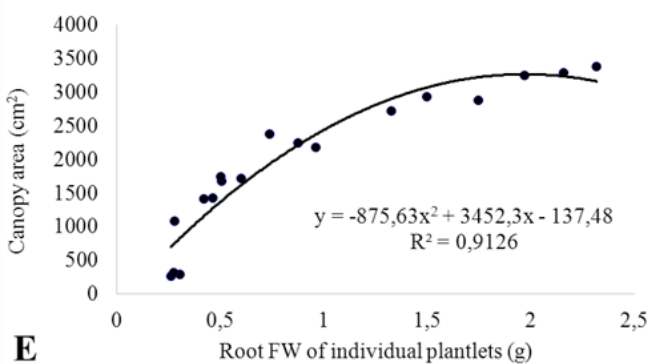

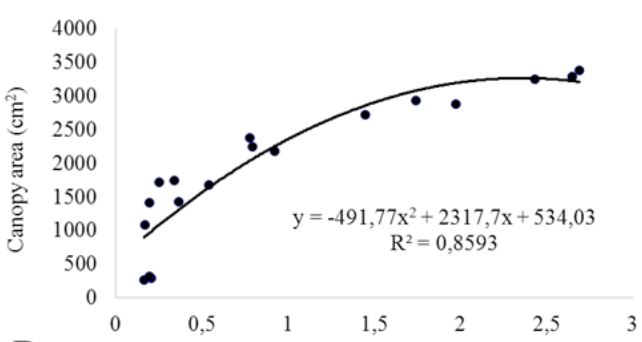

B

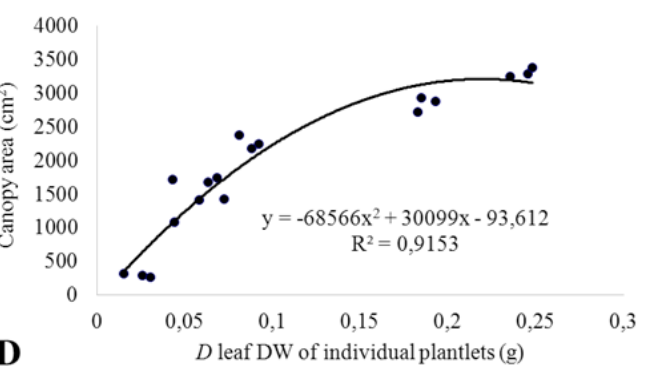

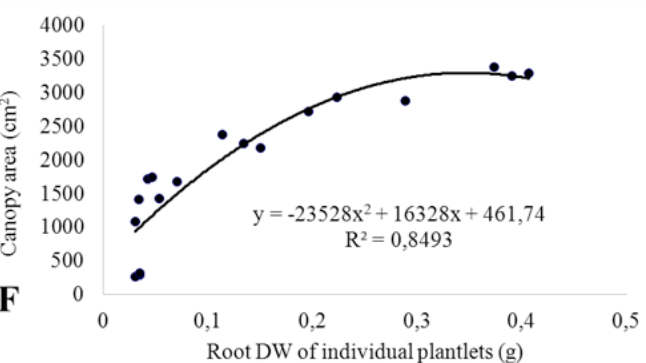

Fig. 4: Relationship between canopy area of 56 pineapple plantlets measured with the automated image analysis procedure (y) and individual plantlet growth during acclimatization. $\mathrm{R}^{2}$ are statistically different from cero $(\mathrm{p} \leq 0,05 ; \mathrm{n}=18)$. FW: fresh weight. DW: dry weight. 
Fig. 4 show the mathematical relationships (parabolas) between automated canopy area assessments and the fresh and dry weights of individual plantlets, including roots, stem and leaves (Fig. 4A, B); fresh and dry weights of D leaves (Fig. 4C, D), and fresh and dry weights of roots (Fig. 4E, F). The determination coefficients (R2) ranged between 0.84 and 0.92 , which are regarded as high in biological research (28).

\section{Discussion}

There have been several published reports on the use of automated image analysis techniques to determine the area of plant canopies. Aguilar et al. (29) studied the leaf area index in tomato plants in a greenhouse and reported an R2 value of 0.75 with the manual method. Minervini et al. (30) established an automated image analysis method for Arabidopsis phenotyping with $96.7 \%$ accuracy. Subsequently, these authors developed Phenotiki, an open-source hardware and software platform for image-based phenotyping of rosette-shaped plants (31). Similarly, Ubbens et al. (32) also reported on the application of image analysis phenotyping in rosette plants and achieved R2 values of 0.82 . Rincon Guerrero et al. (33) used different types of cameras for image analysis, to study leaf area in several species, namely Syngonium podophyllum, Codiaeum variegatum, Citrus spp., Tradescantia zebrina and Malviscus arboreus. These authors obtained R2 coefficients in the region of 0.98 . Finally, Guo et al. (34) developed a novel algorithm for image analysis to investigate canopy coverage in a rice paddy, reporting R2 values of 0.99 . These are just some examples of research demonstrating the effectiveness of image analysis in studies investigating canopy dynamics in a diverse range of crops.

Our work describes the application of image analysis to monitor the progression of canopy development in micropropagated pineapple during the first five months of acclimatisation. This method is easy to carry out, non-destructive and objective. In the current study, blocks of 56 plantlets were photographed every month, and their canopy area was automatically determined. Strong correlations were found between canopy area measurements from image analysis and destructive measurements of plant fresh and dry mass for intact plantlets, D leaves and roots. These data indicated the efficacy of image analysis for canopy estimations in pineapple.

There was also an excellent correlation between the data obtained by the semi-automated and automated image analysis, but with a substantial difference in the time required for each of the two methods The the semi-automated procedure took approximately 4 hours per image, whereas the automated method could be completed in 0.27 seconds (Intel(R) Core(TM) I3$41603.6 \mathrm{GHz}$ and 8 GB RAM).

An additional advantage of the automated system is that the HSI colour system of this method is closer to how humans perceive colours and is less affected by lighting changes that generally occur in acclimatisation greenhouses (35). These observations make the automated method a preferred option when compared with the semi-automated technique. In the context of $\mathrm{H}$ values, values between 30 and 150 were recorded for the pineapple leaves, ranging from pure yellow to the green-cyan border. As these values were not present in the background, it was possible to discriminate between the background and the leaves.

The automated procedure has the potential to save time and reduce research costs in plant phenotyping studies, which could have diverse applications such as investigating the effect of different growth conditions, fertilisation and irrigation regimes, or soil treatments. Furthermore, in plant breeding programmes, automated image analysis has the potential to allow for fast and efficient phenotyping of superior genotypes (or identification of inferior genotypes), particularly when large numbers of samples are evaluated. In the context of pineapple production, image analysis can be used to improve the efficiency of pineapple micropropagation and to design strategies to promote plantlet growth and establishment during the acclimatisation stage.

\section{Acknowledgements}

This research was not covered by any specific grant but supported by internal funds from the Bioplant Centre (Cuba), the Agricultural Research Council-Tropical and Subtropical Crops (South Africa), and the Universitat Politècnica de València (Spain). Authors are also grateful to Mrs Lelurlis Nápoles for her experienced technical assistance.

\section{Conflict of interest statement}

The authors declare no conflict of interest.

\section{Ethical compliance}

This article does not contain any studies involving human participants or animals

\section{References}

1. Chen H, Hu B, Zhao L, Shi D, She Z, Huang X, Priyadarshani S, Niu X, Qin Y. Differential expression analysis of reference genes in pineapple (Ananas comosus 1.) during reproductive development and response to abiotic stress, hormonal stimuli. Trop Plant Biol 2019; 12: 67-77.

2. Nath V, Kumar G, Pandey S, Pandey S. Impact of climate change on tropical fruit production systems and its mitigation strategies. In: Sheraz Mahdi S (ed.) Climate Change and Agriculture in India: Impact and Adaptation. 2019. Springer, Berlin, pp. 129-146.

3. Priyadarshani S, Cai H, Zhou Q, Liu Y, Cheng Y, Xiong J, Patson DL, Cao S, Zhao H, Qin Y. An efficient Agrobacterium mediated transformation of pineapple with GFPtagged protein allows easy, non-destructive screening of transgenic pineapple plants. Biomolecules 2019; 9(10): 617.

4. Wali N. Pineapple (Ananas comosus). In: Nabavi S, Sanches Silva A (eds.) Nonvitamin and nonmineral nutritional nupplements. 2019. Elsevier, pp. 367-373.

5. Escalona M, Lorenzo JC, González B, Daquinta M, Borroto C, González JL, Desjardines Y. Pineapple micropropagation in temporary immersion systems. Plant Cell Rep 1999; 18: 743-748. 
6. Gómez D, Escalante D, Hajari E, Vicente O, Sershen, Lorenzo JC. Assessing the effects of in vitro imposed water stress on pineapple growth in relation to biochemical stress indicators using polynomial regression analysis. Not Bot Horti Agrobot Cluj 2020; 48: 162-170.

7. Daquinta M, Benegas R. Brief review of tissue culture of pineapple. Pineap News 1997; 3: 7-9.

8. Botella J, Fairbairn D. Present and future potential of pineapple biotechnology. Acta Hort 2005; 622: 23-28.

9. Wang M-L, Uruu G, Xiong L, He X, Nagai C, Cheah K, Hu J, Nan G-L, Sipes B, Atkinson H. Production of transgenic pineapple (Ananas comosus (L.) Merr.) plants via adventitious bud regeneration. In Vitro Cell Dev Biol-Plant 2009; 45: 112-121.

10. Loyola-González O, Medina-Pérez MA, Hernández-Tamayo D, Monroy R, Carrasco-Ochoa JA, García-Borroto M. A pattern-based approach for detecting pneumatic failures on Temporary Immersion Bioreactors. Sensors 2019; 19(2): 414.

11. Parveen S, Mir H, Ranjan T, Pal AK, Kundu M. Effect of surface sterilants on in vitro establishment of pineapple (Ananas comosus (L.) Merill.) cv. Kew. Curr J Appl Sci Technol 2019; 33(2): 1-6.

12. Venâncio JB, Araújo WF, Chagas EA. Acclimatization of micropropagated seedlings of pineapple cultivars on organic substrates. Científica 2019; 47: 52-61.

13. Yanes-Paz E, González J, Sánchez R (2000) A technology of acclimatization of pineapple vitroplants. Pineap News 2000; 7: 5-6.

14. González R, Laudat T, Arzola M, Méndez R, Marrero P, Pulido L, Dibut B, Lorenzo JC. Effect of Azotobacter chroococcum on in vitro pineapple plants' growth during acclimatization. In Vitro Cell Dev Biol-Plant 2010; 47(3): 387-390.

15. González R, Serrato R, Molina J, Aragón C, Olalde V, Pulido L, Dibut B, Lorenzo JC. Biochemical and physiological changes produced by Azotobacter chroococcum (INIFAT5 strain) on pineapple in vitro-plantlets during acclimatization. Acta Physiol Plant 2013; 35: 3483-3487.

16. Mengesha A, Ayenew B, Tadesse T. Acclimatization of in vitro propagated pineapple (Ananas comosus (L.), var. Smooth cayenne) plantlets to ex vitro condition in Ethiopia. Am J Plant Sci 2013; 4(2): 317-323.

17. Rodríguez-Escriba RC, Rodríguez R, López D, Lorente GY, Pino Y, Aragón CE, Garza Y, Podestá FE, González-Olmedo JL. High light intensity increases the CAM expression in "MD-2" micro-propagated pineapple plants at the end of the acclimatization stage. Am J Plant Sci 2015; 6(19): 3109-3118.

18. Rodríguez-Escriba RC, Rodríguez-Cartaya ID, Lorente GY, López D, Izquierdo RE, Borroto LS, Garza-García Y, Aragón CE, Podestá FE, Rodríguez R. Efecto del déficit hídrico sobre cambios morfo-fisiológicos y bioquímicos en plantas micropropagadas de piña MD-2 en la etapa final de aclimatización. Cult Trop 2016; 37: 64-73.

19. Lorente-González GY, Pino-Legrat Y, Rodríguez-Escriba RC, Pérez-Borroto LS, Nápoles-Borrero L, Mendoza-Rodríguez J, Cardoso D, Alonso A, Rodríguez-Sánchez R, González-Olmedo J. Foliar fertilization of 'MD-2' pine- apple plants (Ananas comosus var. comosus) during the acclimatization phase. Newsletter of the Pineapple Working Group, International Society for Horticultural Science 2018; 25: 13-17.

20. Atkinson JA, Lobet G, Noll M, Meyer PE, Griffiths M, Wells DM. Combining semi-automated image analysis techniques with machine learning algorithms to accelerate large-scale genetic studies. GigaScience 2017; 6: gix084.

21. Pound MP, Atkinson JA, Townsend AJ, Wilson MH, Griffiths M, Jackson AS, Bulat A, Tzimiropoulos G, Wells DM, Murchie EH. Deep machine learning provides state-ofthe-art performance in image-based plant phenotyping. GigaScience 2017; 6: gix083.

22. Gupta SD, Ibaraki Y, Pattanayak A. Development of a digital image analysis method for real-time estimation of chlorophyll content in micropropagated potato plants. Plant Biotech Rep 2013; 7: 91-97.

23. Niazian M, Sadat-Noori SA, Abdipour M, Tohidfar M, Mortazavian SMM. Image processing and artificial neural network-based models to measure and predict physical properties of embryogenic callus and number of somatic embryos in ajowan (Trachyspermum ammi (L.) Sprague). In Vitro Cell Dev Biol-Plant 2018; 54: 54-68.

24. Ollier M, Talle V, Brisset AL, Le Bihan Z, Duerr S, Lemmens M, Goudemand E, Robert O, Hilbert JL, Buerstmayr $\mathrm{H}$. Whitened kernel surface: A fast and reliable method for assessing Fusarium severity on cereal grains by digital picture analysis. Plant Breed 2019; 138: 69-81.

25. Wang G, Sun Y, Wang J. Automatic image-based plant disease severity estimation using deep learning. Comp Intel Neurosci 2017; 2017: 2917536.

26. Asaari MSM, Mishra P, Mertens S, Dhondt S, Inzé D, Wuyts N, Scheunders P. Close-range hyperspectral image analysis for the early detection of stress responses in individual plants in a high-throughput phenotyping platform. ISPRS J Photogram Rem Sens 2018; 138: 121-138.

27. Py C, Lacoeuille JJ, Teisson C. L'ananas, sa culture, ses produits. Techniques agricoles et productions tropicales vol. 33. Maisoenneuve and Larose 1984; Paris, pp. 44-45.

28. Ivanov Z. The Agricultural Experimentation 1989. Pueblo y Educación, Havana, pp. 332.

29. Aguilar M, Pozo J, Aguilar F, García A, Fernández I, Negreiros J, Sánchez-Hermosilla J. Application of close-range photogrammetry and digital photography analysis for the estimation of leaf area index in a greenhouse tomato culture. Int Arch Photogram Rem Sens Spat Inf Sci 2010; 38(5): 5-10.

30. Minervini M, Abdelsamea MM, Tsaftaris SA. Image-based plant phenotyping with incremental learning and active contours. Ecol Inf 2014; 23: 35-48.

31. Minervini M, Giuffrida MV, Perata P, Tsaftaris SA. Phenotiki: An open software and hardware platform for affordable and easy image冈based phenotyping of rosette冈shaped plants. The Plant J 2017; 90: 204-216.

32. Ubbens J, Cieslak M, Prusinkiewicz P, Stavness I. The use of plant models in deep learning: an application to leaf counting in rosette plants. Plant Meth 2018; 14: 6.

33. Rincón Guerrero N, Olarte Quintero MA, Pérez Naranjo JC. Leaf area measurement in photographs taken with a 
webcam, a cell phone or a semi professional camera. Rev Fac Nac Agron Medellín 2012; 65: 6399-6405.

34. Guo W, Zheng B, Duan T, Fukatsu T, Chapman S, Ninomiya S (2017) EasyPCC: benchmark datasets and tools for high-throughput measurement of the plant canopy coverage ratio under field conditions. Sensors 2017; 17: 798.

35. Chien C-L, Tseng D-C (2011) Color image enhancement with exact HSI color model. Int J Innov Comp Inf Cont 2011; 7: 6691-6710. 